\title{
Local Culture Preservation through Southern Thainess-Based English Lessons
}

\author{
BUDSABA KANOKSILAPATHAM \\ Faculty of Management Science, Silpakorn University, Petchaburi IT Campus, Sam Phraya Sub- \\ district, Cha-am District, Petchaburi Province 76120, Thailand \\ kanoksib@gmail.com
}

Published online: 20 October 2020

To cite this article: Budsaba Kanoksilapatham. 2020. Local culture preservation through Southern Thainess-based English lessons. KEMANUSIAAN the Asian Journal of Humanities 27(2): 179-199. https://doi.org/10.21315/kajh2020.27.2.10

To link to this article: https://doi.org/10.21315/kajh2020.27.2.10

\begin{abstract}
Due to the existing trend of English as a global language, coupled with the emerging trend of regionalisation, individual national culture and identity have attenuated. Concerns regarding the increasing influx of foreign influence through a multitude of channels have been exacerbated by the augmented popularity of social media that permeates most aspects of people's lives. As a consequence, particularly in the Thai context, Thai culture and identity is vulnerable. This presentation represents an attempt to avoid such imminent subjugation and simultaneously preserve the national identity of Thai learners. Specifically, this study highlights local cultural features pertaining to southern Thailand, manifested through a set of English lessons constructed and subsequently implemented to elementary students in southern Thailand for ten weeks. Based on the tests devised to measure the students' southern Thailand knowledge and associated English vocabulary, the southern Thainess-based English lessons exert a significantly positive impact on English language learning and cultural awareness. As demonstrated, the local culture-based English lessons can be manipulated as a viable and legitimate channel to address learners' local culture. By extension, English education can be deemed as an ideal and promising avenue to integrate other academic disciplines to empower learners to be equipped for the demands of the 21 st century.
\end{abstract}

Keywords and phrases: southern Thainess, local culture, preservation, young learners, English lessons

\section{Introduction}

The current established status of English as a global language has been triggered by the trend of globalisation. Consequently, the majority of people around the world are enticed by this status because it means that communication across 
the globe is facilitated through the use of the English language. However, some people are feeling troubled or worried for fear that their own native language is decreasing in popularity. In addition, a number of characteristics associated with national identities which have been shaped by national history and passed down for generations are possibly being jeopardised. These concerns regarding the increasing influx of influence generated by, or related to, the English language through a multitude of channels have been exacerbated by the augmented popularity of social media that permeates most aspects of people's lives.

Along this line of argument, Thai culture and identity, without exception, can possibly be vulnerable to subjugation and eventually extinction. The Thai scenario can be quite alarming, with the unstoppable English influence and the influx of social media. In fact, Thai people were ranked as one of the top highest social media users in 2017 (The Bangkok Post 2018). As a consequence, Thai culture and identity are highly susceptible to vulnerability. In addition to social media, another factor contributing to the imminent subjugation of Thai culture is that young generations in Thailand do not seem to have clear understanding, awareness, or recognition of Thai culture. Valuable national and cultural norms and values are thus dismissed by these young generations because they prefer to follow, and behave in tandem with, foreign cultural norms and values. Spencer-Oatey and Franklin's $(2012,13)$ notion of "cultural diffusion" thus seems to capture the phenomenon being described in Thailand. Cultural diffusion refers to the situation where two or more cultures are in contact, triggering the spread of the cultures on one group of people to another. For example, similar to Thailand, in Indonesia, Asfima and Ovilia (2016) maintained that Indonesians, especially the younger generation, are likely to adapt to western culture. However, as asserted by them, the stake is high because they tend to adopt this western culture indiscriminately, ignoring their own rich Indonesian culture.

The scenario has been exacerbated by another important factor. Thailand is losing ground both regionally and internationally with regard to Thai citizens' English competence. To elaborate, the results of English tests taken by Thai citizens, be they national or international, have been labelled as "unsatisfactory" across the educational paradigm (Kanoksilapatham 2016; Kanoksilapatham and Channuan 2018; Kanoksilapatham and Suranakkharin 2018). So, from the language learning perspective, even though this state of Thai learners' poor English competence has been prevalent for some time, attempts by numerous sectors to improve Thai learners' English have not had a hugely positive impact.

Given the emergence of the digital era and the ubiquity of social media, a few scholars in Thailand began to explore the merits of integrating social media 
content in developing learners' English language skills (e.g., Chotipaktanasook 2016; Sitthirak 2013; Tananuraksakul 2015). In these studies, English language instruction designed based on social media content (e.g., Facebook and Twitter) and accompanied by scaffolding tasks and activities substantially improved learners' language skills. However, it should be noted that for young learners being exposed to social media content without additional scaffolding or support to reinforce language use, it is very unlikely that they will be capable to sifting through the content in order to gain substantial language learning benefits, not to mention the inherent negative impact of social media on their Thai culture repertoire.

At this juncture, it is evident that the strive to improve Thai citizens' English education and the maintenance and preservation of national Thai culture or identities may seem to be putatively contradictory. However, it is not necessarily the case that Thai identity needs to be sacrificed for the sake of improving English proficiency, or vice versa. In fact, these two forces can be harnessed to provide mutual support which eventually will lead to augmented English proficiency and enhanced awareness of Thai identity or national culture. A number of countries have been quite successful with integrating local cultural features into target language instruction. Some of the examples of this include the Your Language My Culture (YLMC) Project in Terengganu, Malaysia, for secondary school students by Nambiar, Hashim and Yasin (2018), the studies on university students in Indonesia by Nurlia and Arini (2017) and by Kartini et al. (2019) in Saudi Arabia.

To elaborate, for instance, in Malaysia, a set of local culture-based English learning materials implemented to secondary schools proved to be successful, as assessed by focus group interviews of both students and teachers (Nambiar, Hashim and Yasin 2018). This example shows that these two forces are in fact not contradictory, but can be used to mutually enhance each other. Based on the positive outcome of language learning as illustrated in a number of Asian countries mentioned above, this study, as an extension, may help to preserve Thai culture and ameliorate English language learning by integrating Thai identity features into English instructional materials. Specifically, this article primarily justifies the crucial need to integrate Thai local cultural features into English lessons by the systematic development of such lessons, the implementation of the developed lessons to a southern Thai school for a period of ten weeks and finally the assessment of the implementation. Based on a number of assessment results, the integration of Thai local cultural features into English lessons has proved to be promising by not only preserving the local culture of southern Thailand, but also augmenting southern Thai learners' English vocabulary competence associated with the local culture. 


\section{Local Culture and Language Learning}

The notion of integrating local culture into language materials has been asserted and maintained by a number of renowned scholars (e.g., Byram 1997; Byram and Fleming 1998; Foley and Thompson 2003; Kramsch 2001; Risager 2008; Saluveer 2004). According to these scholars, culture is integral to language learning and thus language and culture are inseparable. Since language learning cannot take place in a vacuum, a social context is needed to make language learning meaningful. However, at this juncture, the notion of culture can possibly generate a variety of pedagogical approaches and practices, reflecting a number of levels and contexts of cultural integration. Some English Language Teaching (ELT) practitioners agree that emphasising the role of target language cultural features contributes to a better understanding of how the language works in a particular context. It is thus assumed that, being exposed to the target language used in context will facilitate the process of language learning. In contrast to this view, it can be argued that a focus on the target language culture might not be one of the most effective method. That is, other ELT practitioners consider that focusing on the target language culture seems to be inadequate because English is currently used as a lingua franca. This means that learners need to be aware of the culture not only pertaining to the target language but also to other languages. In this approach, multicultural awareness seems to be prioritised and anticipated to be more beneficial for language learners (Risager 2008; Saluveer 2004). From this perspective, despite the fact that Thai learners of the English language currently have substantial exposure to the target language culture through social media and communication technology, their English proficiency is still limited. Therefore, it is challenging to examine whether exposing Thai learners of English to Thai local cultural features would lead to positive learning outcomes.

\section{Young Learners of English and Local Thai Culture-Based Materials: Pedagogical Challenges}

Although it is established that the integration of culture (be it of the target language or local culture) is pedagogically beneficial - a number of issues in relevance to this matter and corresponding teaching approaches focusing on culture need to be thoroughly considered, including a number of variables related to learners, teachers and learning contexts. Moreover, although it is undeniable that being multi-culturally cognisant is advantageous, this goal might not be appropriate nor attainable for young learners who generally have relatively limited exposure to even their native culture and very likely scant exposure to the target language culture. Therefore, requiring them to be aware of multicultural features may be too daunting, challenging, or even impossible. Moreover, in order for these young 
learners to understand and appreciate the target language culture and subsequently compare and contrast distinguishing cultural features, they need to have enough language facilities to allow them to communicate or express their cross-cultural knowledge. Therefore, developing local culture awareness for young learners seems to be prerequisite, more feasible, more profitable, more plausible and more realistic.

Even though elementary education is the grassroots of the entire educational paradigm and thus deserves our immediate attention, a number of previous studies have demonstrated that local culture-based materials can be advantageous among high school and university students in diverse contexts (Kartini et al. 2019; Khan 2014; Nambiar, Hashim and Yasin 2018; Nguyen 2017; Nurlia and Arini 2017; Sudartini 2012). Therefore, it remains to be determined whether these positive impacts can be observed in the Thai context and at elementary level.

Each culture, be it local, national, or international, is complex, encapsulating a myriad of distinguishing characteristic features, including language, customs, tourist attractions, foods, festivals, superstitions, lifestyle, clothing, values, traditions, beliefs, art and morals. Moreover, some of the constructs are somewhat concrete and tangible, whereas the others are relatively abstract. To accommodate the young age of elementary students, concrete Thai cultural features that are relevant to the Thai learners' background seem to be the optimal option for pedagogical practices.

At this juncture, Stern (1992, 223-232) explicitly presents a number of relevant suggestions when teaching culture. Among them are creating an authentic classroom environment, providing cultural information and making use of cultural community resources. The concern regarding what aspects of culture to be integrated with the teaching materials is a crucial pedagogic issue. As known, in certain environments or contexts, specific cultural values might not always be in harmony with the learners' local values. As Khan (2014) cautioned and exemplified, for instance, in Saudi Arabia, the learning context is characterised as a somewhat "restricted society". Therefore, integrating culture into learning materials must be meticulously executed so that any adverse effects on learners' behaviours and conflicts with their way of life or norms can be avoided.

\section{This Study}

This study represents an attempt to illustrate that English language instruction can be harnessed as a channel to fulfil the obligations of developing Thai people's English competence and preserving Thai identity. Specifically, English 
instructional materials were employed as a device to instil both local cultural knowledge and English language knowledge. As demonstrated by previous studies in diverse national and academic contexts (e.g., Kartini et al. [2019] in Indonesia for university students; Nambiar, Hashim and Yasin [2018] in Malaysia for lower secondary students), integrating local culture into English lessons has proved to be potentially beneficial. This study focuses on young Thai learners in public elementary schools. Since it is known that each part of Thailand has its own unique cultural features, southern Thai cultural features were focused on in this study. Therefore, Thai national culture or identity in this study is subcategorised as the cultural features or Thainess features pertaining to southern Thailand.

Among a number of multiple constructs of Thai culture, tourist attractions were chosen to be one of the resources that serves the purpose of this study. Although people tend to align culture with tradition, according to United Nations Educational, Scientific and Cultural Organization (UNESCO) (2009) culture encompasses value, beliefs, ways of living, etc. The target participants of this study are young Thai learners in rural areas who are likely to have limited experience and exposure to Thai culture. Consequently, the lesson topics appropriate for them should be relatively concrete and tangible. At this juncture, individual tourist attractions display a number of cultural dimensions or perspectives including history, geography, biology, environment, art, way of life, food, tradition, ecology, etc. As recognised nationally and internationally, southern Thailand has a plethora of tourist attractions due to its exquisite sea landscapes which can be appreciated from diverse dimensions. For example, Samila Beach in Songkhla Province in southern Thailand is very famous not only for its gorgeous beauty but also romantic legendary mermaid statue that has become the landmark of the province. In addition, Phra That temple, which contains the Buddha's relics and the Pattani Central Mosque, the largest mosque in Thailand with exquisite architectural structures where Muslims gather to pray and listen to sermons, strengthening their communal bond. The temple and the mosque thus interestingly display how the two cultures co-exist in this particular region of Thailand. It is hoped that, with the exposure to the English lessons based on southern Thai tourist attractions to begin with, the learners will be equipped with the lesson content and the language so that they can express their southern Thai identity realistically and meaningfully.

\section{Methodology}

Prior to the presentation of the methodological features of this study, for an accurate and better understanding of the scenario in focus, it is essential that contextual information about English education and pedagogical policies in Thailand be described. Because the participants of this study are young Thai learners in public 
schools, this section opts to focus solely on public elementary English education in Thailand.

\section{English Language Teaching in a Thai Context}

English in Thailand has the status of a foreign language. English language teaching in Thailand dates back to the 1820s. Initially, English was exclusively taught to people in the upper class and later it was made accessible to other citizens as a device to modernise and develop the country. Recently, the demand for English in Thailand has been exponentially increasing in response to the ongoing trend of globalisation and the establishing of ASEAN Economic Community in 2015. English education in public elementary schools is mandatory, under the supervision of the English Language Institute, Basic Education Commission, Ministry of Education. A six-year programme from Grades 1 to 6 focuses on four language skills of listening, speaking, reading and writing. The adoption of the CEFR for benchmarking communicative language competence in 2014 means that, upon the completion of Grade 6, elementary students are supposed to attain the A1 level. Although communicative language teaching has been recommended as a principal teaching approach, many Thai teachers of English find it challenging to shift from the traditional grammar translation approach. As for class time allocation, at least one hour of English learning per week for Grades 1 to 3 and two hours per week for Grades 3 to 6. Additional English learning is possible if a school is ready.

Even though a large amount of budget is allocated to improve English education, based on the national and international outlook, the success seems to be minimal. Therefore, many parents, if they can afford it, would like to have their children attend schools that offer English programmes (e.g., Mini English Programme, International Programme and English Bilingual Education Programme) which are mushrooming in Thailand. Several factors identified to be responsible for Thai learners' unsatisfactory achievement in English include: the typical characteristics of Thai learners who are shy and afraid to make mistakes, lack of opportunities to practice English and shortage of qualified English teachers (Kanoksilapatham 2014). As far as instructional materials are concerned, all textbooks used are endorsed by the Ministry of Education and can vary from one school to another. Typically, these commercial textbooks are written by native speakers of English and published by international publishers.

\section{Objectives}

The objectives of this article are twofold, i.e., to determine whether southern Thainess-based language materials could enhance: (1) the participant's local 
cultural knowledge and (2) their English vocabulary knowledge associated with southern Thainess.

\section{Materials Construction: Southern Thai Culture-Based English Lessons and Tests}

Language materials development is a crucial stage of this study because it can determine the learning outcomes to a certain extent. In this study, the materials development phase entails a number of steps including identifying the learners' needs and determining language tasks and activities. In order to construct a set of English language materials with content validity, addressing the community needs and resources (Stern 1992; Tomlinson 2011), needs analysis was conducted.

Initially, a questionnaire was devised, consisting of a list of 46 tourist attractions located in southern Thailand. The questionnaire was distributed and completed by local southern Thai residents (14 provinces; 100 each), asking them to identify the eight most popular tourist attractions pertinent to southern Thailand. In so doing, the integration of the English language and local cultural learning was represented by a set of teaching materials. At this stage, based on a total of 1,400 questionnaires completed and received, the eight highest frequency counts representing eight local tourist attractions were identified. Subsequently, eight corresponding English lessons were individually developed and expanded to cover the major points of the individual attractions. To illustrate what two of the lessons look like, Figures 1 and 2 represent parts of Lesson 2: Samila Beach, one of the most famous beaches and the whole lesson of Lesson 4: Temple and Mosque, two sacred places highly respected by Buddhists and Muslims in southern Thailand.

All of the eight lessons follow the same format, beginning with new vocabulary introduction, followed by a set of six to eight reading sentences containing all of the words previously introduced. For vocabulary, 10 words associated with the lesson content were carefully selected. To facilitate the young learners' comprehension of the meaning, corresponding translations in Thai (L1) are provided. In order to expose the students to language use in context, all the words presented are used in the reading part highlighting specific information about individual tourist attractions. At this juncture, to make sure that these words capture the learners' attention, the target words embedded in the sentences are highlighted (Schmidt 1993). 

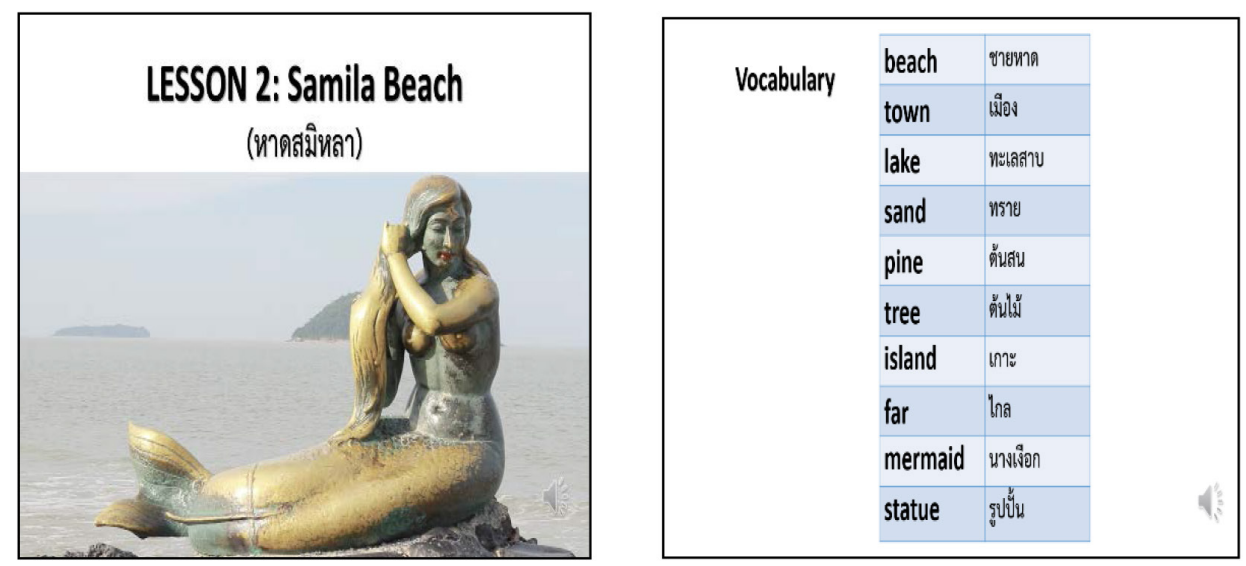

\section{Samila Beach (ทาศสิมลล)) is in Songkhla.}

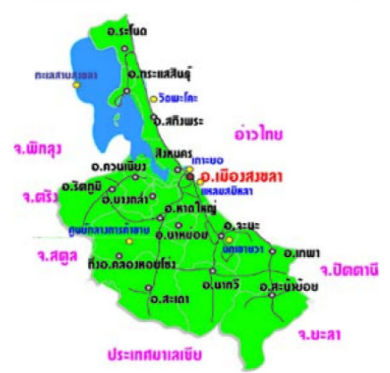

It is a part of Songkhla town.

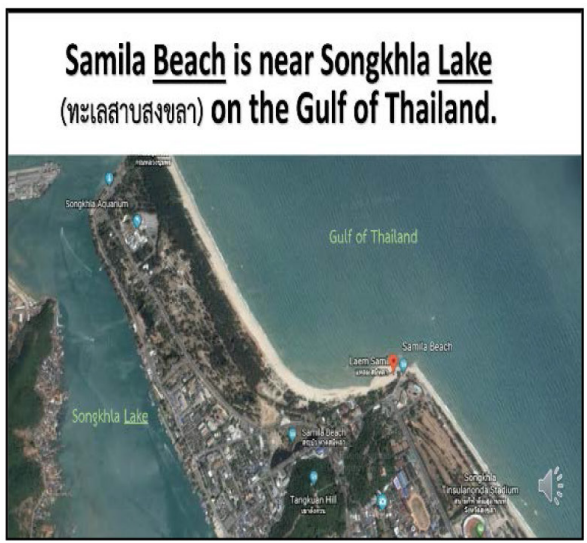

The sand of Samila Beach is white.
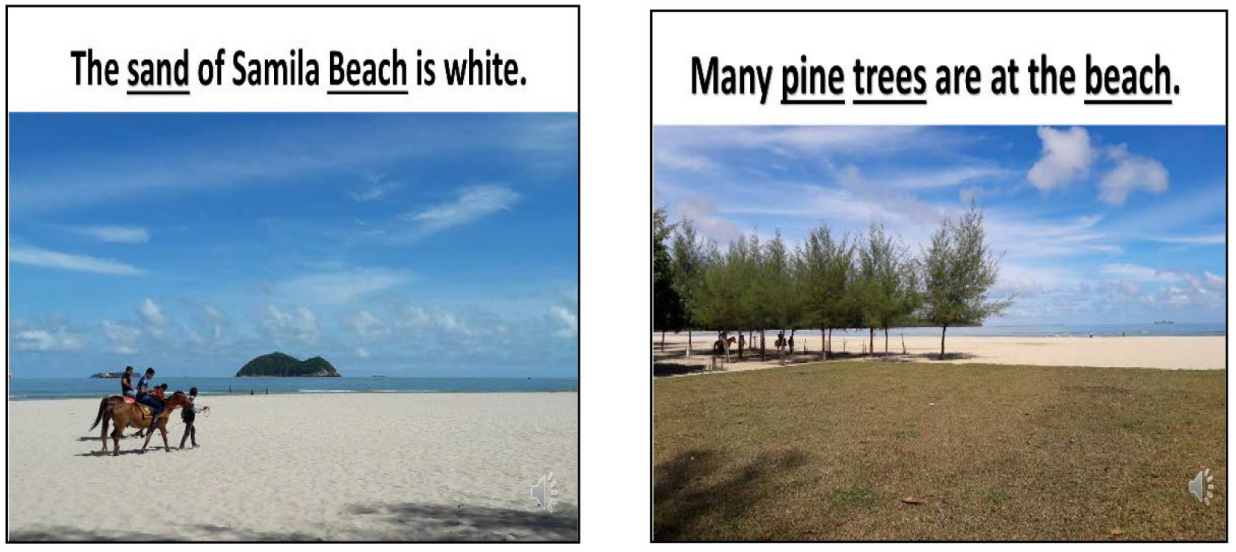

Figure 1. Lesson 2: Samila Beach 

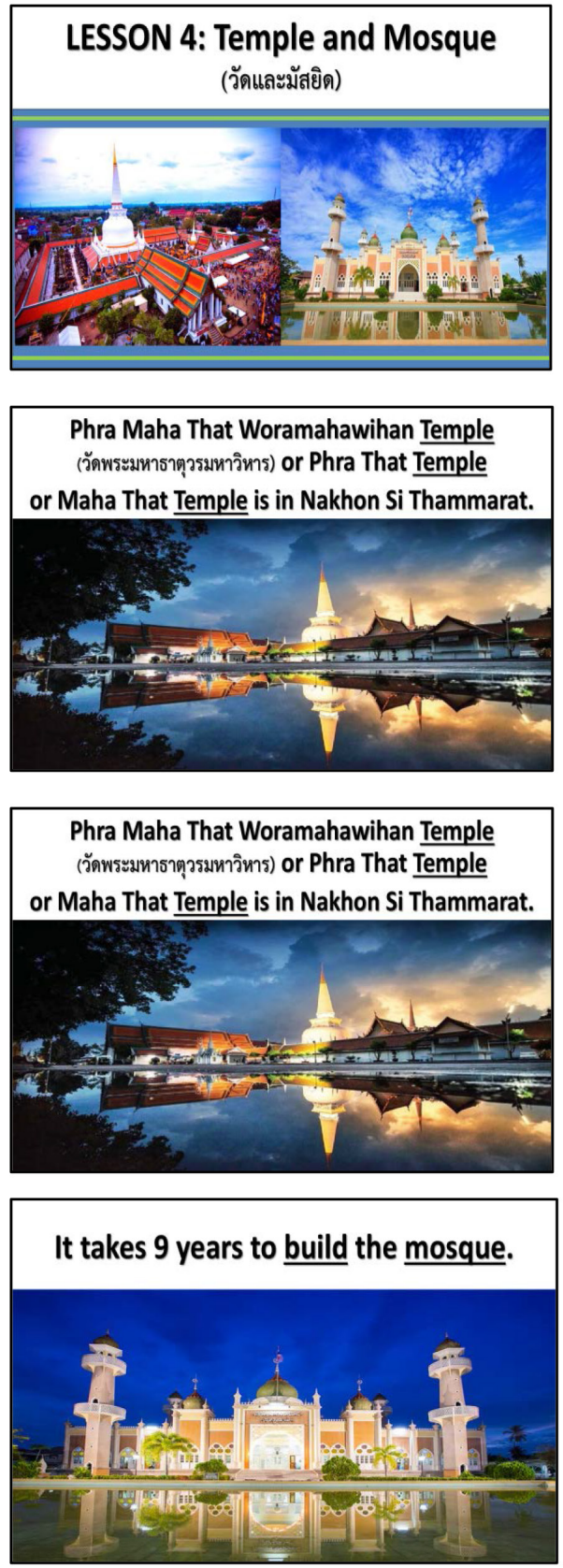
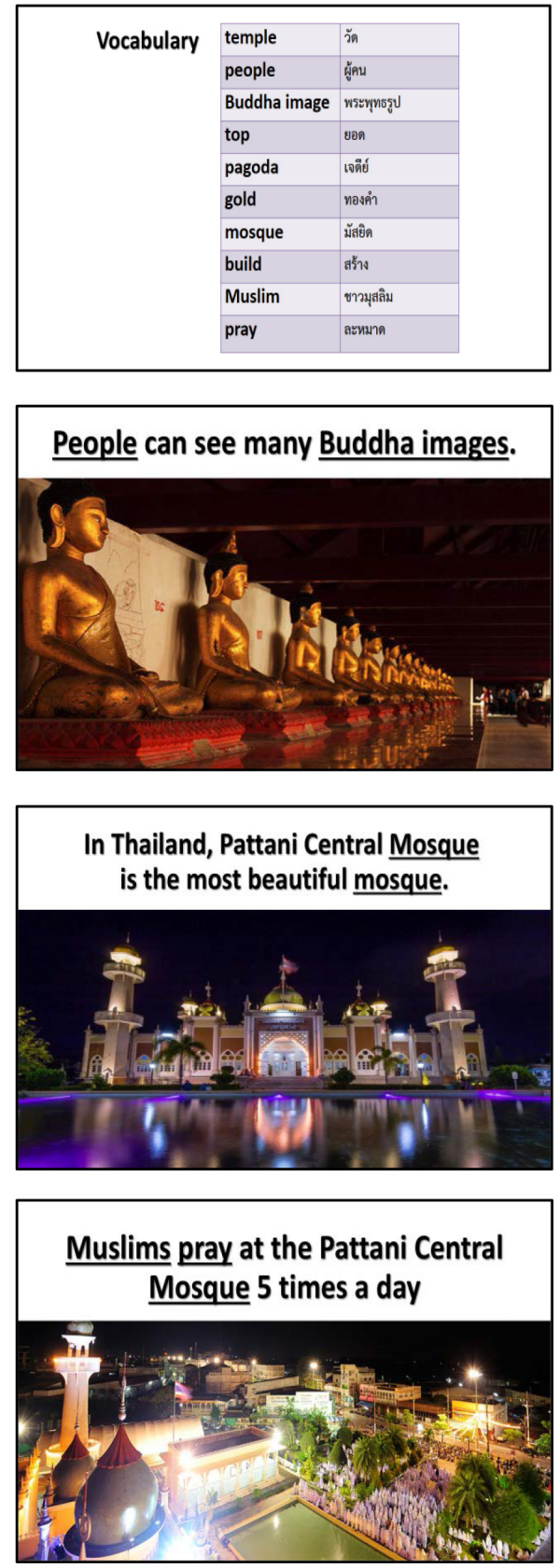

Figure 2. Lesson 4: Temple and Mosque 
According to Tomlinson (2011), teaching materials systematically designed and constructed should create an atmosphere that scaffolds learners' language learning, improves their knowledge and enriches their language experience. In addition, following suggestions made by Herron et al. (1999) and Stern (1992), to accommodate the learners' young age and to compensate for the need to provide real-life exposure to the local culture, corresponding multimedia of the eight attractions were produced to scaffold their language learning.

In addition to these eight lessons, two sets of similar pre/post-tests of 40 items each were generated based on the language materials. The objectives of these tests are to monitor and reinforce the learners' learning outcome in two areas: local southern Thai knowledge and English vocabulary associated with southern Thailand tourist attractions. The tests were designed to accommodate the young age of the learners. That is, the southern Thainess knowledge test requires the learners to complete the statements provided in Thai. The total score for this part is 40 points, one point each. Misspelled answers were not penalised as long as they made sense. As exemplified in Figure 3, the five questions were generated from one lesson (Lesson 2: Samila Beach).

1. Samila Beach is in the province of

2. Samila Beach is close to the Gulf of

3. At Samila Beach, there is a statue of a

4. At Samila Beach, there are many trees.

5. Two islands not far from Samila Beach are and

Figure 3. Thainess test

As far as the vocabulary test is concerned, the test requires the learners to choose one of the four pictures in Figure 4 presented on the overhead projector that matched the word read twice. As shown in Figure 4, the word read is "beach" and the learners were supposed to mark "b" on the answer sheet. Similar to the southern Thai knowledge test, only five items were generated from each lesson, yielding a total of 40 test items of 40 points in total. 
(a)

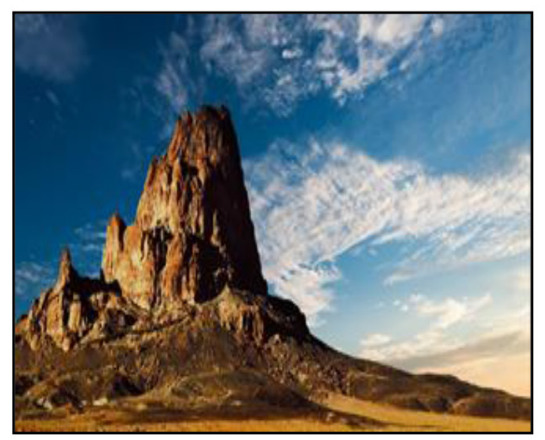

(c)

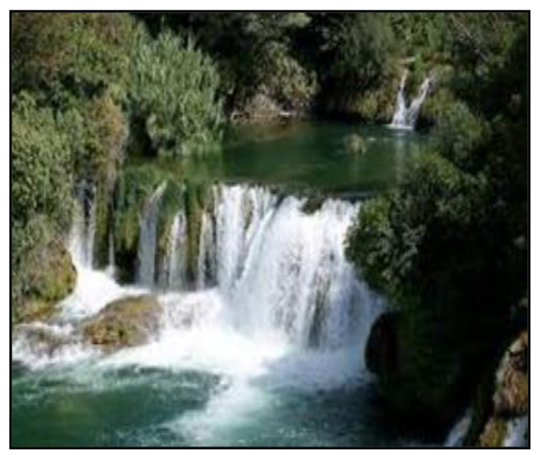

(b)

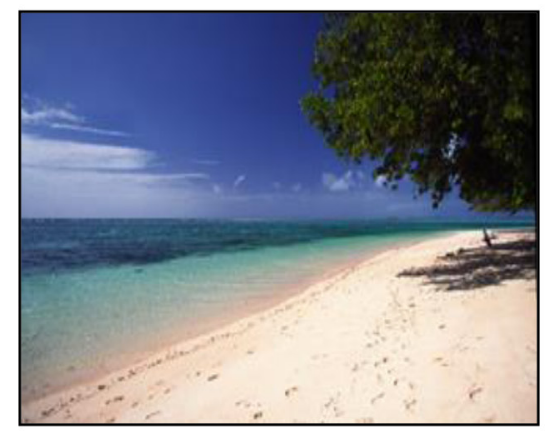

(d)

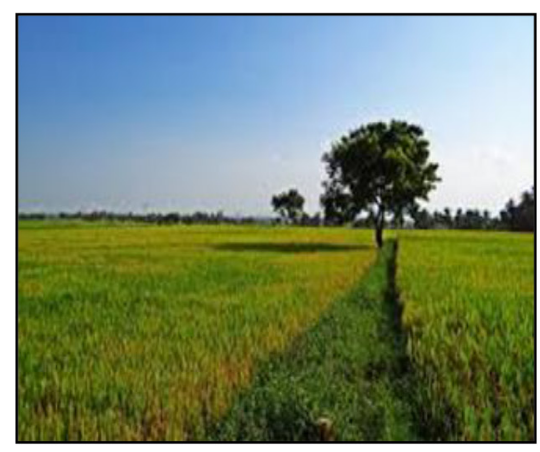

Figure 4. Vocabulary test

\section{Participants}

This study was conducted at one public school randomly selected in the southern part of Thailand. Although English education in Thailand is compulsory from Grade 1, many schools are not ready to implement the English curriculum until Grade 3, a common phenomenon particularly in the rural areas. The one basic requirement for the school to be able to participate in this project is the availability of computer technology for the lessons and corresponding multimedia materials to be presented to learners. Among the entire range from Grade 1 to 6 classes, only one class of Grade 4 (aged 10 to 11) was selected because Grade 4 students would have had a certain level of English lesson exposure, allowing the lessons produced to be able to develop their previous knowledge of English. Grade 6 was not considered a potential option because in the second semester, these Grade 6 students are busy with the national test preparation. In short, Grade 4 students seem to be the ideal group to participate. 


\section{Procedures: Instructional Materials Implementation}

The implementation stage of this study lasted for 10 consecutive weeks. It needs to be noted that this 10 -week long project is intervening in nature. That is, the students continued with their mainstream courses and the Principal agreed to integrate two extra class periods for this project in 2018. The instruction was delivered by the researcher, with the school English teacher in the classroom for every session as a helper with classroom management. In Week 1, the southern Thainess and English vocabulary pre-tests were administered separately to establish their knowledge of southern Thainess and vocabulary prior to instruction. Then, the eight lessons developed were implemented for a period of eight weeks (from Week 2 to Week 9), each week for two class periods of 50 minutes.

The methodology of Activity-Based Learning (ABL) was adopted in this study. It is the process of learning by doing. In this $A B L$ approach, learners are encouraged to actively participate in their own learning experience through practical activities (Putnam and Borko 2000). Dorjiss (2013) maintains that ABL contributes to the vibrance of the classroom and learners' enhanced motivation. In this study, a range of learning tasks and activities were devised, including games, role-play, pair work and group work. Although the details of the designed activities vary depending on the topics of individual lessons, basically, in each week, the lesson began with the presentation of the target vocabulary. Since mastering the meaning of the target words is one of the ultimate goals of the lesson, games and tasks employed are meaning-oriented. With the slides or the pictures associated with individual tourist attractions projected on the screen, the activities were much facilitated, arousing the learners' curiosity of the lessons and allowing them to connect the target words with the tourist sites. Pronunciation was also emphasised so that these learners were confident when uttering the words. To informally assess their meaning and pronunciation knowledge of the target words, based on the pictures or slides presented, the learners - be they individual or as a team-were encouraged to say a word that they know with correct pronunciation. The class usually ended with the students watching the videos of individual tourist attractions. Often times, the students requested to watch the videos again when the class time permitted. Finally, in Week 10, the last week of the project, the two similar sets of southern Thainess and vocabulary post-tests were administered.

All of the test scores (pre-tests and post-tests of southern Thainess and vocabulary) were collected and subsequently analysed using descriptive statistics, followed by a $t$-test to establish whether the knowledge gained, if any, is significant. 


\section{Results}

This section presents two major findings regarding the young learners' knowledge of southern Thainess and their associated vocabulary. As shown in Table 1, the class consists of 31 Grade 4 students, of which 17 are boys and 14 are girls. The average southern Thai knowledge pre-test score was 8.24 and it rose to 24.72 after the instruction, indicating that the lessons could impart the local Thainess knowledge. This increase is statistically significant $(t=-12.37, p<0.05)$. As for English vocabulary knowledge, the learners had an average score of 16.60 and 29.76, before and after instruction, respectively. Similar to the southern Thainess gain score, their vocabulary gain score was substantially significant $(t=-8.530$, $p<0.05)$.

Table 1. Southern Thainess and English vocabulary test scores $(n=31)$

\begin{tabular}{lcccccc}
\hline & \multicolumn{3}{c}{ Southern Thainess } & \multicolumn{3}{c}{ English vocabulary } \\
\hline & Pre-test & Post-test & Score & Pre-test & Post-test & Score \\
Min. & 3 & 12 & 5 & 10 & 15 & 2 \\
Max. & 19 & 38 & 30 & 25 & 40 & 22 \\
Mean & 8.24 & 24.72 & 16.65 & 16.60 & 29.76 & 13.10 \\
\hline \multicolumn{3}{c}{$t=-12.37, p<0.05$} & \multicolumn{3}{c}{$t=-8.530, p<0.05$} \\
\hline
\end{tabular}

\section{Discussion}

This section highlights two major findings of the increased knowledge of southern Thainess and associated English vocabulary. The findings regarding the gained knowledge after the learners' exposure to the instructional materials are in congruence with those of other scholars (e.g., Kartini et al. 2019; Nambiar, Hashim and Yasin 2018 - in Malaysia), confirming the positive impact of local culture-based English lessons in the context of southern Thailand. The findings also demonstrate that the local culture-based English lessons can contribute not only to the preservation and maintenance of local culture in young learners but also the expansion of their English language vocabulary.

One of the major reasons contributing to the positive learning outcome includes the fact that the content of the English lessons is relevant to the learners' life and experience or so-called schemata (Rumelhart 1980; Xiao-hui, Jun and Wei-hua 2007). Therefore, once their southern Thainess schemata were activated by the lessons, they were able to connect with the lessons, facilitating their acquisition of southern Thainess culture and English vocabulary pertaining to southern Thainess. If the materials were about the target language cultural features, the young learners 
might encounter certain obstacles in trying to understand the lesson contents, not to mention a higher level of difficulty in trying to grapple with a set of unfamiliar vocabulary items pertinent to the target language culture. It can be envisaged that, in this scenario, the difficulty encountered by the learners does not purely lie in the matter of understanding the teaching materials but also in retaining the learned material due to the lack of connection with their daily life schemata.

Because of the learners' accomplishment, be it in English vocabulary or southern Thainess knowledge, by extension, their motivation to learn English could have been boosted because they could visualise a realistic value in learning English. That is, they are learning English not because the subject is compulsory, but because they realise that it can serve as a device for them to express their southern Thai identity in English. These findings congruently corroborate the schema theory (Rumelhart 1980; Xiao-hui, Jun and Wei-hua 2007), which is acknowledged to exert a positive impact on language learning. In addition to enhanced English competence, the learners can develop Thai cultural competence, rendering them to be more knowledgeable about their own community.

In this study, especially in the vocabulary test, the young students, as scaffolded by a set of four pictures for each item, were allowed to demonstrate their gained vocabulary knowledge. As seen and described earlier, the vocabulary test posed a minimal threat to them because this particular task did not require them to produce extended linguistic output. This finding clearly illustrates that for young learners, language tasks or tests need to be cautiously designed, taking the learners' age into consideration. Additionally, the words tested were carefully selected; in fact, they were directly associated with the lesson contents, or, in other words, their schemata. Thus, learning new vocabulary items was facilitated. Once the students are familiar with the contents of the tourist attractions and vocabulary associated with them, they can then focus on other language aspects, making the task of language learning generally less intimidating.

It is acknowledged that the ultimate goal of language learning is to be successful in communication and to be culturally knowledgeable. Consequently, English language teaching and teaching cultural features accompanying the English language cannot be separated. However, cultural competence is not limited to the learners' native culture knowledge but extends to multi-culture knowledge. This study aims to prepare the learners in that direction. That is, local culturebased instruction and teaching provides an avenue to primarily appreciate their own culture as a tool to express themselves. Subsequently, they will be more than ready to be exposed to other cultures in the future, sharpening their intercultural 
competence (Sercu 1998; 2005), allowing them to better satisfy international or multicultural demands and to be a competent citizen.

In line with the national education goals of improving Thai citizens' English and satisfying the community's expectations, it seems that the most fruitful way is integrating the local Thai cultural values in the practice of English language teaching to promote not only English education but also Thai national identity education. This kind of achievement has been reported in other contexts. For instance, Nambiar, Hashim and Yasin (2018) integrated local culture into supplementary reading materials to improve communication abilities of Malaysian lower secondary school learners. Also in Malaysia, David and Govindasamy (2017) demonstrate how English language textbooks produced for use in schools can help promote national identity and enhance the country's global outlook. The analysis of the names used in the textbooks endorsed by the Ministry of Education reveals that, for example, major ethnic groups in Malaysia are represented, through the use of Indian names, Chinese names, Muslim names, etc. Finally, in the context of Vietnam, Van Van (2016) highlights the design and development of the tenyear English textbook series for the entire paradigm of Vietnamese schools under the National Foreign Languages 2020 Project. In addition to language knowledge and language skills, intercultural knowledge is emphasised. The topics familiar to the Vietnamese and suited to the learners' age were included in the textbooks. For instance, the integration of the nation's unique geographical landscapes and national cultural features in the textbooks exerted a strong positive impacts on young learners, making them feel proud of their country. Additionally, the lessons featuring local cultural features awakes an insatiable curiosity about their own context, motivating them to pay more attention to the lessons (Kanoksilapatham and Khamkhien 2020).

Based on the previous accounts and the findings generated by this study, it can be seen that young learners can play a role as active cultural agents who are knowledgeable of their own native culture. With additional exposure to cultural diversity and their sharpened sensitivity to cultural variation as they grow up, their role can be expanded including maintaining the spirit of nationalism and serving as cultural ambassadors who are ready to express their own identity and to understand and appreciate other people's identity.

However, it should be noted that culture is multifaceted, socially constructed, dynamic and evolving due to political or social modifications (Nieto 2010, 137144). Therefore, in the long run, to be cognisant of cultural competence, the lessons need to be able to integrate national, regional and international culture effectively as the learners grow and become more mature. In order for the learners to cope 
with more challenging tasks triggered by abstract concepts of cultural issues, the same principles and approaches as this study can be adopted or adapted to provide instructional materials that are relevant to the more mature learners' needs and English proficiency and in accordance with the environment and context of the learners. For example, the lessons can be more linguistically challenging, with increasing grammatical complexity and more varied vocabulary to adequately represent a myriad of local culture characteristics (e.g., environment, geography, way of life, food, dress, rituals, art and history). Additionally, more challenging and authentic tasks and activities need to be devised for more mature learners (Fenner 2000). Due to the young age of the learners in this study and safety reasons, the tourist attractions were introduced to the class in the form of multimedia materials. However, for mature learners, experiential learning by exposing them to the actual tourist attractions will arouse their curiosity, appreciation and motivation. In so doing, a simulated tour guide task conducted at the sites could be very stimulating, practical and realistic.

The set of instructional materials developed in this study were employed as supplementary materials to scaffold mainstream English teaching. In this regard, even though the learners appeared to be enthusiastic and happy during the class time, to assure that the positive impact is genuinely rooted from the instructional materials, interviews need to be conducted with the learners and the school teachers who were observing the class throughout the project period. In addition, for sustainable development of the learners' English competence, it remains to be established whether these learners have positive attitudes towards this kind of teaching. The findings will help elucidate the actual impact of the materials and the instruction and allow other researchers to delve into this issue.

To further consolidate the positive impact of the English lessons integrating local culture, an additional experimental study in determining whether the instruction that integrates local culture can be more effective than a teaching without a localised context needs to be conducted. Further studies are also needed to explore the impact and the retention of the impact of the local culture and vocabulary knowledge.

All in all, this study demonstrates that a set of local Thainess-based English lessons can enhance the learners' linguistic ability and Thainess knowledge. Further challenges include investigating the learners' ability in conducting a meaningful task, like a simulated tour guide task, so that the benefits of integrating culture into an English lesson can be empirically assessed. Other activities that can encourage the learners to demonstrate their speaking and writing abilities can be illuminating. Considering the urgent need to maintain national identity and the ubiquitous role 
of English, integrating local cultural features into the teaching and learning of English is clearly beneficial.

\section{Conclusion}

This study highlights the prime focus of integrating local culture when designing and creating instructional materials for the target language. As demonstrated by the findings, such integration facilitated the target language learning as far as vocabulary is concerned. Based on the findings, it can be concluded that English lessons relevant to the students' experience as developed in this study yields a contributing and positive outcome, particularly in the area of cultural awareness and English vocabulary. However, it remains to be investigated whether these learners can subsequently transfer their vocabulary and southern Thai knowledge in performing language tasks such as speaking or writing. Given the centrality of Thailand as one of the most popular tourist hubs in the region, it would be interesting to determine whether these young learners could perform a tour guide task, integrating both southern knowledge and vocabulary. Pedagogically, this study provides guidelines to English education fellows with regard to how to construct appropriate and satisfactory materials for young learners of English in Thailand. From the learners' perspective, being able to use English to express their own identity at an early age, the local-culture based English lessons can provide an impetus, motivation and a justified reason for Thai learners to learn English.

\section{Acknowledgements}

This article was developed from the presentation at the Fifth International Conference on Linguistics, Literature and Culture (ICLLIC) on 29 to 30 July 2019 at The Wembley Hotel, George Town, Pulau Pinang, Malaysia. This research project was supported by the Thailand Research Fund under the research grant no. RTA588007. Without kind assistance from different individuals including the research team members, the southern residents, the school administrators and teachers and particularly the students, this project would not have been possible.

\section{References}

Asfima, R. and Ovilia, R. 2016. Be proud of Indonesian cultural heritage richness and be alert of its preservation efforts in the global world. Humanus XV(2): 195-206. https://doi.org/10.24036/jh.v15i2.6428

Byram, M. 1997. Cultural awareness as vocabulary learning. Language Learning Journal 16(1): 51-57. https://doi.org/10.1080/09571739785200291 
Byram, M. and Fleming, M. 1998. Language learning in intercultural perspective approaches through drama and ethnography. Cambridge: Cambridge University Press.

Chotipaktanasook, N. 2016. Using social media in the EFL classroom for the enhancement of low affective filter and willingness to communicate. Paper presented at the Seventh CLS International Conference (CLaSIC 2016), Singapore, 1-3 December.

David, M.K. and Govindasamy, S. 2017. The construction of national identity and globalization in multilingual Malaysia. In Language policy, culture and identity in Asian contexts, eds. B.M. Tsui and J.W. Tollefson, 55-72. New York: Routledge. https://doi.org/10.4324/9781315092034-4

Dorjiss. 2013. Activity based teaching method. Teaching Strategy, 5 May. Retrieved from http://dorjigss.blogspot.com/2013/05/normal-0-false-false-false-en-us-X-none.html.

Fenner, A.S. 2000. Cultural awareness. In Approaches to materials design in European textbooks: Implementing principles of authenticity, learner autonomy and cultural awareness, eds. A.B. Fenner and D. Newby, 141-150. Graz, Austria: European Centre for Modern Languages.

Foley, J. and Thompson, L. 2003. Language learning. London: Arnold.

Herron, C., Cole, S.P., Corrie, C. and Dubreil, S. 1999. The effectiveness of video-based curriculum in teaching culture. The Modern Language Journal 83(4): 518-533. https://doi.org/10.1111/0026-7902.00038

Kanoksilapatham, B. 2016. Promoting global English while forging young northeastern Thai learners' identity. 3L: The Southeast Asian Journal of English Language Studies 22(3): 127-140. https://doi.org/10.17576/3L-2016-2203-09

- 2014. Thai elementary school teachers' English pronunciation and effects of teacher variables: Professional development. TESL-EJ The electronic Journal for English as a Second Language 18(1): 1-13.

Kanoksilapatham, B. and Channuan, P. 2018. EFL learners' and teachers' positive attitudes towards local community-based instruction. Indonesian Journal of Applied Linguistics 7(3): 504-515. https://doi.org/10.17509/ijal.v7i3.9790

Kanoksilapatham, B. and Khamkhien, A. 2020. The final research report, "English language learning and teaching of our neighboring country: Lessons learned from Vietnam". Nakhon Pathom, Thailand: Silpakorn University.

Kanoksilapatham, B. and Suranakkharin, T. 2018. Celebrating local, going global: Use of northern Thainess-based English lessons. The Journal of Asia TEFL 15(2): 292309. https://doi.org/10.18823/asiatefl.2018.15.2.3.292

Kartini, K., Tolla, A., Jasruddin, J. and Juanda, J. 2019. The design of local culturebased Indonesian language teaching materials. Journal of Language Teaching and Research 10(2): 363-371. https://doi.org/10.17507/jltr.1002.19

Khan, I. 2014. Teachers' perceptions of the significance of local culture in foreign language learning. Journal of English Language and Literature 1(3): 65-70.

Kramsch, C. 2001. Language and culture. Oxford: Oxford University Press.

Nambiar, R., Hashim, R.S. and Yasin, R.M. 2018. Impact of integrating local culture into language materials on communicative ability of Malaysian lower secondary learners. 3L: The Southeast Asian Journal of English Language Studies 24(4): 1326. https://doi.org/10.17576/3L-2018-2404-02 
Nguyen, T.T.T. 2017. Integrating culture into language teaching and learning: Learner outcomes. The Reading Matrix: An International Online Journal 77(1): 145-154.

Nieto, S. 2010. Language, culture and teaching: Critical perspectives. New York: Routledge.

Nurlia, R. and Arini, F. 2017. Effect of bringing local culture in English language teaching on students' writing achievement. The 4th international conference on language, society and culture in Asian contexts, 187-194. Dubai: Knowledge E. https://doi. org/10.18502/kss.vli3.738

Putnam, R.T. and Borko, H. 2000. What do new views of knowledge and thinking have to say about research on teacher learning? Educational Researcher 29(1): 4-15. https://doi.org/10.3102/0013189X029001004

Risager, K. 2008. Language and culture: Global flows and local complexity. Cambridge: Cambridge University Press.

Rumelhart, D. 1980. Schemata: The building blocks of cognition. In Theoretical issues in reading comprehension, eds. R.J. Spiro, B.C. Bruce and W.F. Brewer, 33-58. Hillsdale, NJ: Erlbaum. https://doi.org/10.4324/9781315107493-4

Saluveer, E. 2004. Teaching culture in English classes. MA diss., University of Tartu.

Schmidt, R. 1993. Awareness and second language acquisition. Annual Review of Applied Linguistics 13: 206-226. https://doi.org/10.1017/S0267190500002476

Sercu, L. 2005. The future of intercultural competence in foreign language education: Recommendations for professional development, educational policy and research. In Foreign language teachers and intercultural competence: An international investigation, ed. L. Sercu, 160-181. Clevedon, UK: Multilingual Matters. https:// doi.org/10.21832/9781853598456-012

. 1998. In-service teacher training and the acquisition of intercultural competence. In Language learning in intercultural perspective approaches through drama and ethnography, eds. M. Byram and M. Flemming, 255-289. Cambridge: Cambridge University Press.

Sitthirak, C. 2013. Social media for language teaching and learning. Retrieved from https://www.academia.edu/2612052/Social_Media_for_Language_Teaching_and_ Learning.

Spencer-Oatey, H. and Franklin, P. 2012. What is culture. A compilation of quotations. Coventry, UK: GlobalPAD/University of Warwick.

Stern, H.H. 1992. Issues and options in language teaching. Oxford: Oxford University Press.

Sudartini. 2012. Inserting local culture in English language teaching to promote character education. Jurnal Pendidikan Karakter 1: 45-54.

Tananuraksakul, N. 2015. An investigation into the impact of Facebook group usage on students' affect in language learning in a Thai context. International Journal of Teaching and Learning in Higher Education 27(2): 235-246.

The Bangkok Post. 2018. Thailand makes top 10 in social media use, 1 March. Retrieved from https://www.bangkokpost.com/business/news/1420086/thailand-makes-top10-in-social-media-use.

Tomlinson, B. 2011. Material development in language teaching. Cambridge: Cambridge University Press. 
United Nations Educational, Scientific and Cultural Organization (UNESCO) Institute. 2009. The UNESCO framework for cultural statistics. Canada: UNESCO Institute.

Van Van, H. 2016. Renovation in curriculum design and textbook development: An effective solution to improving the quality of English teaching in Vietnamese schools in the context of integration and globalization. VNU Journal of Science: Education Research 32(4): 9-20. https://doi.org/10.25073/2588-1159/vnuer.3845

Xiao-hui, L., Jun, W. and Wei-hua, W. 2007. Analysis of schema theory and its influence on reading. US-China Foreign Language 5(11): 18-21. 